\title{
Scrotal Advancement Flap for Giant Condyloma Accuminatum
}

\section{Alana Harrison*, Beshoy Nashed, Wesley High, Burt Faibisoff and Raul Lopez}

Mountain Vista Medical Center, Mesa, Arizona, United States

\begin{abstract}
Buschke-Lowenstein tumors are very large, fungating masses usually in the perineal region and are associated with Human Papilloma Virus (HPV). There have been many cases of large masses requiring excision, but on our literature review we were not able to find any that underwent partial closure with a scrotal advancement flap.
\end{abstract}

Keywords: Buschke-Lowenstein; Condyloma; Advancement flap; Plastic Surgery; HPV

\section{Introduction}

Condyloma growths are fairly uncommon and affect only 289 per 100,000 people worldwide [1]. It appears most growths are diagnosed early on, when the lesions are still small and amendable to nonsurgical treatment. Treatment options utilized are laser, radiotherapy, intralesional interferon alfa, or topic imiquimod [2]. These, however, are not effective treatments for large tumors. Buschke- Lowenstein tumors are giant condylomas that are locally invasive and exhibit malignant behavior, but are predominantly benign histologically [3]. They are universally caused by HPV, which is the most common sexually transmitted disease of the anorectum [4]. HPV subtypes 6 and 11 typically cause non-malignant warts and type 16 and 18 are more commonly malignant [4]. This type of tumor is between condyloma accuminatum and squamous cell carcinoma on the scale of malignancy with a transformation risk of $30-50 \%$. The mainstay treatment is surgical resection with clear margins. Chemotherapy and radiation is not a mainstay and should be utilized only in unresectable cases. At time of resection a diverting loop colostomy can be performed to aid in healing of the wound, but is not always necessary [5]. There have been many cases reported in literature that involve resection and different types of closure such as V-Y advancement flaps and pedicled thigh flaps $[4,6]$. The goal of this case report is to explore different options for skin coverage of this difficult area.

\section{Case Presentation}

This is a case of a 49 -year-old Caucasian male with a complex history of extensive genital warts requiring several excisions and subsequent recurrences over the past 30 years, referred to us for a large genital mass. His most recent excision was 8 months prior to presenting to our office. It included debulking of penile, scrotal and anal condylomas for 2 hours. The recurring lesions expanded more aggressively, coalescing into one giant lesion causing significant perineal pain, itching and foul drainage. The patient's medical history was notably positive for: Hepatitis C, a history of rectal fistulas requiring four fistulectomies, and a history of methamphetamine abuse. On exam, the lesion was an obvious extreme case of Giant Condyloma Acuminatum, or BuschkeLowenstein tumor. It extended from the anal area to the base of the scrotum and bilaterally to the mid-gluteal regions, measuring about 15 $\times 12 \mathrm{~cm}$ (Figure 1).

\section{Surgery}

We carefully dissected the scrotal lesion with laser technology. All staff present in the OR wore N95 masks to prevent HPV DNA entering airways, as a known risk from several studies. It was found to be tunneled and communicated with the perineal condyloma. A wide excision was performed allowing complete removal of the condyloma, including off of the anterior anal verge. The anal verge

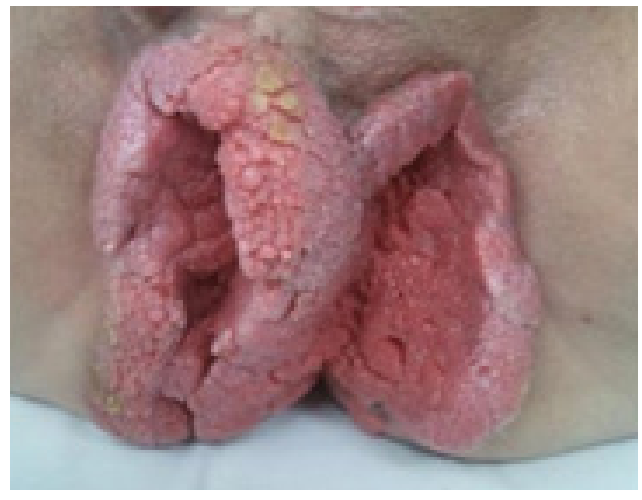

Figure 1: Pre-operative tumor.

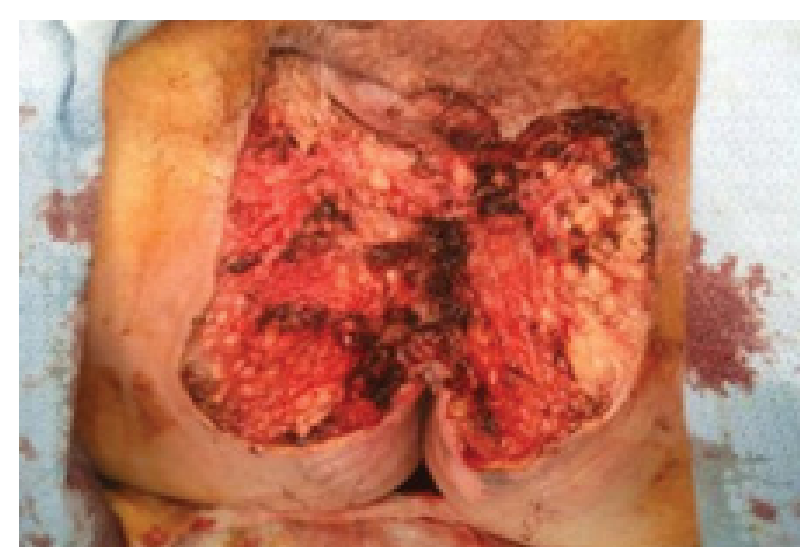

Figure 2: Intraoperative defect after removal of tumor.

was then marsupialized. The wide local circumferential excision of the Bushke-Lowenstein tumor ensued with a resultant $15 \times 15 \mathrm{~cm}$ butterfly defect (Figure 2). Plastic Surgery Portion: The patient had a $15 \times 15 \mathrm{~cm}$ butterfly shaped midline perineal lesion requiring closure.

*Corresponding author: Alana Harrison, Mountain Vista Medical Center, 1301 S. Crismon Road Mesa, AZ 85209, United States, Tel: (480) 358-6158; E-mail aharrison@iasishealthcare.com

Received April 03, 2018; Accepted April 26, 2018; Published May 05, 2018

Citation: Harrison A, Nashed B, High W, Faibisoff B, Lopez R (2018) Scrotal Advancement Flap for Giant Condyloma Accuminatum. Surgery Curr Res 8: 308 doi: 10.4172/2161-1076.1000307

Copyright: ( 2018 Harrison A, et al. This is an open-access article distributed under the terms of the Creative Commons Attribution License, which permits unrestricted use, distribution, and reproduction in any medium, provided the original author and source are credited. 
The skin margins were undermined about $2.5 \mathrm{~cm}$ on either side for flap advancement. Beneath the scrotum was undermined up to $3 \mathrm{~cm}$. This mobilized the skin well enough to cover $>50 \%$ of the exposed area. The anal verge was marsupialized using 2-0 chromic to give cleanliness. The scrotum was pulled inferiorly about $5 \mathrm{~cm}$ using 2-0 Monocryl sutures. The groin creases were closed in the same manner. Posteriorly bilateral scrotal flap advancements were utilized to approximate the defect and aid in closure (Figure 3) with a resultant defect of $6 \times 4 \mathrm{~cm}$ to close by secondary intention. He developed a hematoma that was evacuated the same day of the primary operation with an otherwise uneventful postoperative course. Postoperative follow ups at 7 weeks and 11 weeks showed good progression and closure of the wound with no signs of residual Condyloma Acuminatum (Figures 4 and 5).

\section{Discussion}

Very large condylomas are reported in journals, but appear to be a relatively uncommon problem. They present as cauliflower lesions in the perianal region [4]. Usually no biopsy or other work up is needed. CT scan may be useful in large cases to evaluate depth of invasion into surrounding tissues. Once diagnosed these lesions require excision

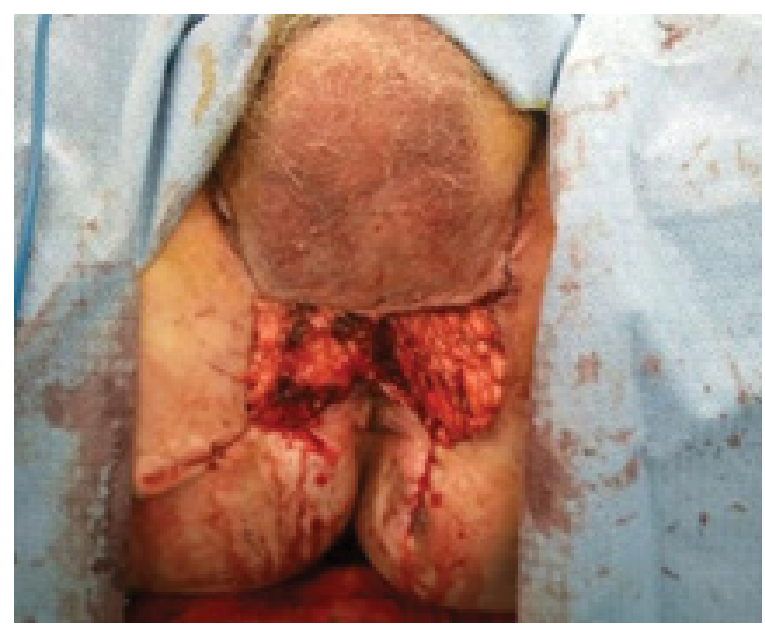

Figure 3: After scrotal advancement flap.

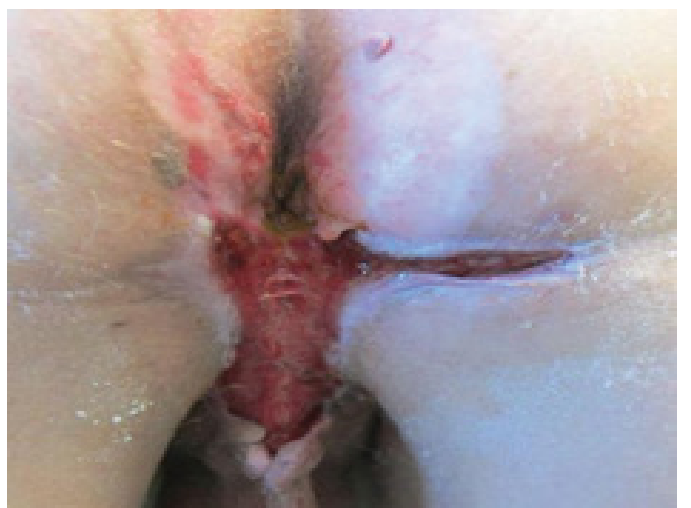

Figure 4: 7 weeks post op.

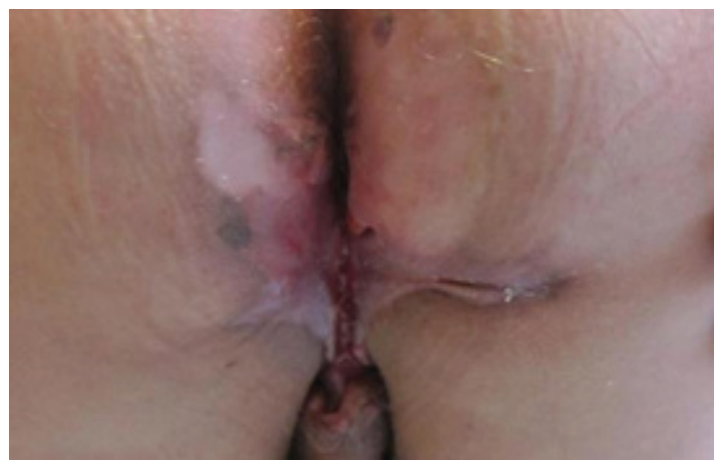

Figure 5: 11 weeks post op.

with negative margins. The tumor usually is located somewhere near the base of the scrotum surrounding the anal region in men and near the anus and labia in women. This location lends itself to at least partial closure with a scrotal flap. In this case we were able to advance the scrotum posteriorly and fill a large portion of the defect. The scrotal flap is a well-known flap used to repair penile loss of skin but we were not able to find any papers on the advancement technique to close large perineal wounds. The scrotum, especially in older men, tends to be very redundant and a large portion can be sacrificed without significant cosmetic defect. This advancement technique worked very well in our case and can be added to the armamentarium of all surgeons dealing with defects around the anal region. Upon our research, there appears to be no perfect way to close large perineal wounds. Other papers have discussed use of V-Y advancement flaps or closure by secondary intention $[4,5]$.

\section{Conclusion}

Large tumors associated with HPV are premalignant, require resection and end up leaving the patient with a large defect in a difficult area to manage. Perineal wounds are fraught with complication from stool soilage and difficulty maintaining clean wounds. Anything the surgeon can do to help heal these wounds quickly is advantageous for these patients. Scrotal advancement flaps are useful and can provide large surface area coverage in select patients.

\section{References}

1. Patel H, Wagner $M$, Singhal $P$, Kothari $S$ (2013) Systematic review of the incidence and prevalence of genital warts. BMC Infectious Diseases 13: 39.

2. Jose Martin M, Molina I, Monteagudo C, Marti N, Lopez V, et al. (2008) Buschke-Lowenstein tumor. J Dermatol Case Rep 2: 60-62.

3. Norton J, Barie PS, Bollinger RR, Chang AE, Lowry S, et al. (2008) Surgery: Basic science and clinical evidence.

4. Gurbulak EK, Akgun IE, Omeroglu S, Ayhan Oz (2015) Giant perianal condyloma acuminatum: Reconstruction with bilateral gluteal fasciocutaneous V-Y advancement flap. Ulus Cerrahi Derg 31: 170-173.

5. Tas S, Arik MK, Ozkul F, Cikman O, Akgun Y (2012) Perianal giant condyloma acuminatum-buschke-lowenstein tumor: A case report. Case Rep Surg 2012 507374

6. Nthumba PM, Ngure P, Nyoro P (2011) Giant condyloma acuminatum of the scrotum in a man with AIDS: a case report. J Med Case Rep 5: 272. 